\title{
Experiments and Simulation on Mannesmann Piercing Process in the Drill Steel Manufacture
}

\author{
Y. Q. Zhao, ${ }^{\mathrm{a}, 1}$ J. H. Mao, ${ }^{\mathrm{b}, 2}$ F. F. Liu, ${ }^{\mathrm{a}, 3}$ and Zh. H. Ma ${ }^{\mathrm{c}, 4}$ \\ ${ }^{a}$ Northeastern University at Qinhuangdao, Qinhuangdao, China \\ b Shenyang Blower Works Group Co Ltd, Shenyang, China \\ ${ }^{c}$ College of Information Science and Engineering, Northeastern University, Shenyang, China \\ ${ }^{1}$ zhaoyanyuqian@163.com \\ 2 maojh-sy@163.com \\ $31013468150 @ q q . c o m$ \\ ${ }^{4}$ mazhenhe@163.com
}

Steel drill rods are employed in the mining industry to drill blast holes in rock, for them a high-quality metal surface and accurate geometrical parameters are essential. Drill steel is a special material exclusively designed for drill rods. To estimate the microstructure and dimensional stability of drill steel, a rigid plastic finite element method (FEM) was applied in examining the Mannesmann piercing in the drill steel manufacture. The three-dimensional thermal-force coupling FEM models were computer-generated with different plug positions. The metal deformation during the piercing process was analyzed in detail. The stress-strain state of the metal ahead of the plug was simulated to obtain formation characteristics during the Mannesmann piercing. The effect of the plug position on force and strain rates was also studied with simulation. The results demonstrate that the dimensional stability of hollow drill rods can be enhanced by advancing the plug position.

Keywords: drill steels, hot rolling, plug position, Mannesmann piercing, rigid plastic finite element.

Introduction. drill steel is a kind of tool steel, which is often used in the mining industry to produce drill rods that are connected with rock drills and drill bits. Usually, drill rods have a hexagonal outer cross section to transfer the torque from the rock drill, and a hollow center to enable high-pressure water to pass and wash the rock powder away [1].

During operation, the rods are subjected to impact loads, which give rise to considerable alternating stresses in the metal. In addition, the rods are subjected to corrosion by the water flowing through the channel. Therefore, rods with high-quality metal surface and accurate geometrical dimensions are demanded.

Many researchers have studied the drill steel. Belousov reported the manufacturing experience with hollow drill steel at various metallurgical plants [1], where a U7 carbon steel billet was employed with a square cross section, having a hole through the center with an EI94 austenite steel core. Larkin et al. developed a technique to manufacture drill rods by using a high-frequency current in the final heat treatment [2]. Postonogov and Nikiforov designed a pass system to roll the hexagon drill steel, which involves oval, edging oval, special leader pass, and open finishing processes. Petrov and Pasynkov analyzed force and torque, and found out the cause of drill rod breakdown is not stability loss but bending deformation of its free end, as a result of deviation of the drill bit from the set direction during spudding due to the unevenness of rock [4]. Song and Rong studied the stress wave theory and strength design principle, and discussed the dynamic responses of fatigue strength of different rod steels under typical technological process [5]. Xing obtained the fatigue test parameters of the tapering connection of drill rods through the analysis of 
combination of stress and strain waves [6]. The service life of drill rods depends on overall performance, drilling conditions, and applied drilling technology. Previous studies are mostly focused on deformation method, final heat treatment, and fatigue strength. However, few of the studies have been reported on the rolling process parameters.

Practically, drill steels are essentially consumable tools in the infrastructure industry. Precision of the size of its inner hole is the most prominent challenge. Figure 1a depicts an ideal cross section of the drill steel, and Fig. 1b shows a photo of the cross section of the drill steel specimen.

As can be seen from Fig. 1, the hexagonal shape of the outer profile is accurate, but the inner hole deviates considerably from perfect circularity. With an increase in ovality and eccentricity, the flexural section modulus decreases, which could then impair the overall performance of drill steels. Therefore, the first step to improve drill steel production is to analyze the effect of process parameters on the precision of the inner hole size.

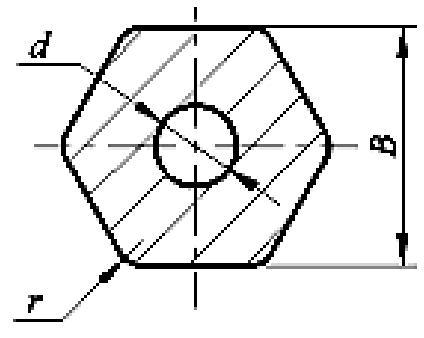

a

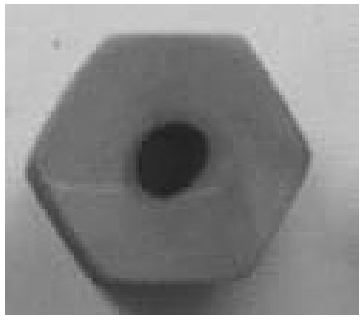

b

Fig. 1. Scheme (a) and photo (b) of the drill steel specimen cross section (B22 type drill steel: $B=22 \mathrm{~mm}, d=6 \mathrm{~mm}$, and $r=2 \mathrm{~mm}$ ).

Piercing is the first deformation process during manufacturing of drill steels, which is affected by its capillary geometry size. The piercing plug position is an important parameter in the process of two-roll rotary piercing. For the Mannesmann two-roll rotary piercing process, we developed a nonlinear finite element model with three-dimensional thermal coupling. The influence of plug position was obtained by implementing simulation for piercing and studying metal deformation and capillary size accuracy.

It is important to improve the overall performance of drill steels and to extend the service life of drill rods. The process of drill steel production is a major factor in determining the overall quality and performance. Therefore, a study of this process has an important theoretical and practical significance.

\section{Materials and Methods.}

1.1. Production Process and Piercing Tools. The main process of heat piercing-heat rolling technology during the production of drill steels involves eight steps. Firstly, the steel rod is cut to the required length. Then, the solid round billet workpiece is heated to $1050^{\circ} \mathrm{C}$ by five DGF-T-502 frequency-induction heaters. The difference between the inside and outside temperatures is maintained at less than $50^{\circ} \mathrm{C}$. Next, the billet workpiece is mechanically centered, cross-rolled and perforated with a Mannesmann two-roll cross rolling mill of $50 \mathrm{~mm}$ diameter. The capillary billet can be reduced with an Accel three-roll cross rolling mill without tension, and followed by hexagonal hot rolling with a rolling mill comprising six symmetrical rollers. As depicted in Fig. 2, the Mannesmann two-roll cross rolling mill consists of roller 1 , blank 2 , plug 3 , and guide plate 4 .

The axes of the upper and lower rollers relative to the billet axis constitute the feed angle $\alpha$. At punch work, the two rollers simultaneously rotate counter clockwise. Due to frictional contact with the rollers, the round billet rotates clockwise and moves forward along the shaft. The plug position $S$ refers to the distance from the center of the nose to 


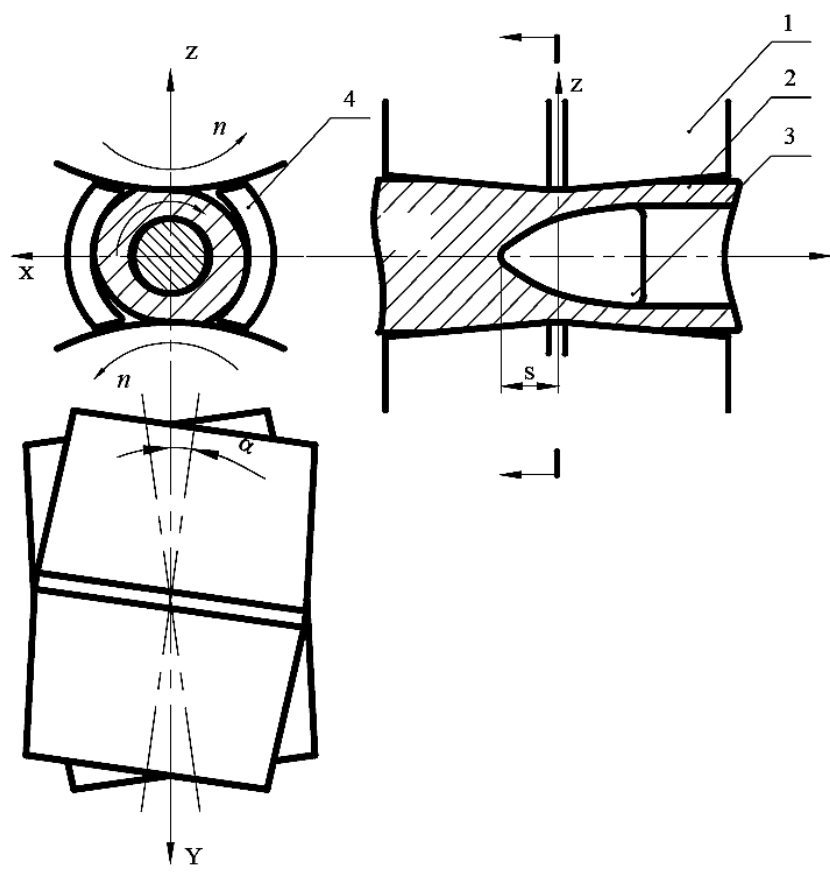

Fig. 2. Schematic diagram of the piercing process.

the center of the roll compression zone, as shown in the right part of diagram in Fig. 2. The plug position directly affects the deformation of the metal, the rolling force, and the precision of the capillary size accuracy. Because the relationship among them is complicated, and moreover, determination of the appropriate plug position is difficult, a suitable plug position can only be obtained by analyzing the interior deformation of the rolled piece.

1.2. Three-Dimensional Modeling. The simulation model of the three-dimensional rigid-plastic finite element was established by DEFORM 3D. DEFORM 3D is the FEM based process simulation system designed to analyze various forming and heat treatment processes, which is widely used in metal forming and related industries. We built the model in the pre-processor and analyzed the results in the post-processor after simulation.

1.2.1. Simulation Controls. Metric unit system, deformation and heat transfer simulation mode were selected in this model as main controls. For step controls, we set: 1 as the starting step number, 300 as the number of simulation steps, 10 as the step increment to save, roller as the primary die, $0.01 \mathrm{~s}$ as the time increment for solution step definition.

1.2.2. Material. The billet of 55SiMnMo steel is used, whose properties are shown in Table 1. 55SiMnMo is a kind of air-cooled bainitic steel, which has relatively low notch sensitivity, microplastic and anti-fatigue strength.

T a b 1 e 1

Properties of 55SiMnMo Steel

\begin{tabular}{|c|c|c|c|c|c|c||}
\hline $\begin{array}{c}\text { Modulus } \\
\text { of elasticity } \\
(\mathrm{Pa})\end{array}$ & $\begin{array}{c}\text { Poisson's } \\
\text { ratio }\end{array}$ & $\begin{array}{c}\text { Density } \\
\left(\mathrm{kg} / \mathrm{m}^{3}\right)\end{array}$ & $\begin{array}{c}\text { Yield } \\
\text { strength } \\
(\mathrm{MPa})\end{array}$ & $\begin{array}{c}\text { Coefficient } \\
\text { of thermal } \\
\text { expansion } \\
\left(\mathrm{K}^{-1}\right)\end{array}$ & $\begin{array}{c}\text { Specific } \\
\text { heat } \\
\text { capacity } \\
(\mathrm{J} /(\mathrm{kg} \cdot \mathrm{K}))\end{array}$ & $\begin{array}{c}\text { Heat } \\
\text { conduction } \\
\text { coefficient } \\
\left(\mathrm{W} /\left(\mathrm{m}^{2} \cdot \mathrm{K}\right)\right)\end{array}$ \\
\hline $2.0 \cdot 10^{11}$ & 0.3 & 7850 & 634 & $1.1 \cdot 10^{-5}$ & 452 & 48 \\
\hline
\end{tabular}


The hot deformation behavior of $55 \mathrm{SiMnMo}$ steel was studied by hot isothermal compression tests at $950-1100^{\circ} \mathrm{C}$ and strain rates of $0.1-10 \mathrm{~s}^{-1}$ using a Gleeble 3500 thermal simulation machine [7].

Under the condition of high temperature plastic deformation, constitutive equations were used to describe the flow stress of the metal used.The hyperbolic sine and exponential equation have been more wildly used under hot working conditions. The Zener-Hollomon parameter $(Z)$ is the temperature-compensated strain rate used to study flow stress and dynamic softening behavior in this paper, using Eq. (1)

$$
Z=\dot{\varepsilon} \exp \left(\frac{Q_{a}}{R T}\right)=B \exp (\beta \sigma)
$$

where $R$ is the universal gas constant, $R=8.314 \mathrm{~J} /(\mathrm{mol} \cdot \mathrm{K}), T$ is the temperature in $\mathrm{K}$, $Q_{a}$ is deformation activation energy in $\mathrm{kJ} / \mathrm{mol}$ indicating the balanced relationship between the work hardening and dynamic softening mechanism at high temperature plastic deformation, and $B$ and $\beta$ are the apparent material constants from hot isothermal compression tests and data regression, the value of $Q_{a}$ is obtained by test at $314,219.8$ $\mathrm{kJ} / \mathrm{mol}, B=9.417 \cdot 10^{12}$, and $\beta=0.0396$.

We calculated peak strain $\varepsilon_{p}$ of $55 \mathrm{SiMnMo}$ steel, using Eq. (2)

$$
\varepsilon_{p}=A d_{0}^{n} Z^{m}
$$

where $d_{0}$ is the initial grain size, $\mu \mathrm{m}, A, n$, and $m$ are the apparent material constants, which can be obtained by test $(A=0.00267, n=0.3$, and $m=0.132)$.

1.2.3. Object Definition. We added five objects to the model, including the up roller, down roller, plug and guide plate as rigid objects, and the blank as plastic object. The respective object geometries were previously input to SolidWorks and saved as STL format. Then we input these STL files into the pre-processor. The grid of the blank is composed of four-node tetrahedral elements, which can be automatically divided according to distributional gradients of strain and strain rates. The rotary speed of the roller is $99 \mathrm{rpm}$, and the initial velocity of the rolled piece is set to $20 \mathrm{~mm} / \mathrm{s}$.

1.2.4. Inter Object Definition. The critical variables to be defined are the friction factor between contacting objects, interface heat transfer coefficient, contact relation and separation criterion.

The friction types allowed in DEFORM are shear and coulomb friction. We chose shear friction because the friction is a function of the yield stress of the deforming body in here. Constant shear friction is used for most bulk-forming simulations. The frictional force in the constant shear model is defined as

$$
f_{s}=m k,
$$

where $f_{s}$ is the frictional stress, $k$ is the shear yield stress, and $m$ is the friction factor. We set 0.3 as the initial friction, which is the typical friction value of hot rolling.

The interface heat transfer coefficient specifies the coefficient of heat transfer between two objects in contact. Three types of thermal boundary condition exist between the rolling surface and the surrounding environment. These include thermal conduction, thermal convection, and thermal radiation. The respective coefficients of heat transfer are set to $0.02,0.9$, and $11 \mathrm{~kW} /\left(\mathrm{m}^{2} \cdot{ }^{\circ} \mathrm{C}\right)$.

The contact relation is used to set the master/slave relationship between the work piece, dies, and deformable bodies. Four master/slave relationships were set in this model, including upper roller/blank, lower roller/blank, plug/blank, guide plate/blank. 
The separation criterion defines how the nodes at the interior object interface will behave when impacted by a tensile force. Generally, normal separation will occur when the contacting node experiences a tensile force or pressure greater than 0.1 .

1.2.5. Database Generation. The simulation parameters were entered into the preprocessor and implemented.

The three-dimensional model is shown in Fig. 3.

With fixed feed angle and other parameters, simulations were performed with eight different plug positions: $0,5,10,15,20,25,30$, and $35 \mathrm{~mm}$. We then analyzed the influence of plug position on the piercing force, the equivalent strain rate, and the size of the capillary.

Next, with fixed plug position and other parameters, simulations were performed with five different feed angles: $8,10,12,14$, and $16^{\circ}$. We then analyzed the influence of feed angle on the piercing force, the equivalent strain rate, and the size of the capillary.

\section{Results and Discussion.}

2.1. Deformation Analysis. The deformation zone can be divided into four areas (Fig. 4).

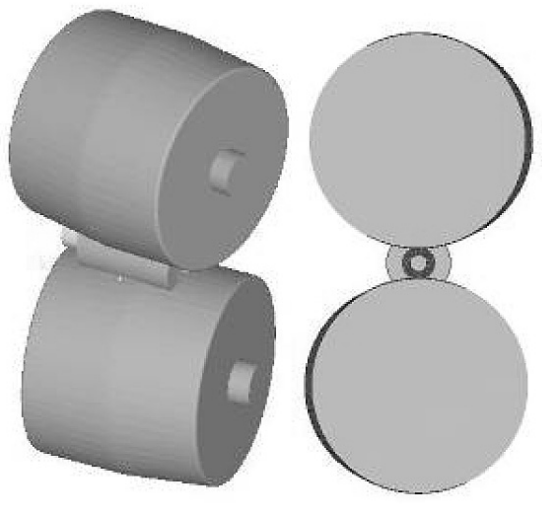

Fig. 3. Three-dimensional model.

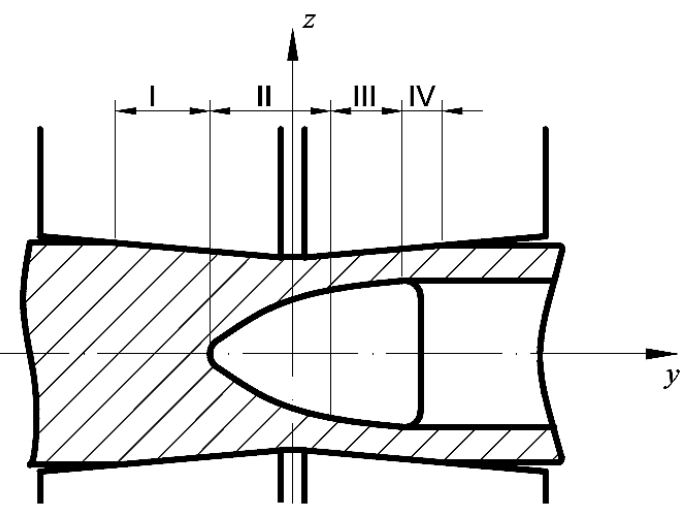

Fig. 4. Scheme of different deformation areas.

Area $I$ is known as the perforation preparation area, in which the solid billet is rolling. In this zone, the billet advances along the rolling direction, gradually being compressed in diameter by the taper of the roller at the inlet. This section of the billet changes from round to oval because of a transverse flow of compressed metal. A bell shaped depression is formed due to the axial flow of the surface metal. The deformation at the exit of area $I$ is shown in Fig. 5a.

There are two 'bites' appearing in the cross piercing process. The first bite occurs with the initial contact between the billet and roller. The second bite occurs with the contact between the billet and plug, as seen in Fig. 5a.

Two bite conditions associated with these contacts must hold simultaneously. The first bite condition is related to the rotating billet,

$$
M_{T} \geq M_{P},
$$

where $M_{T}$ is the rotary friction torque (in $\mathrm{N} \cdot \mathrm{m}$ ) and $M_{P}$ is the positive pressure torque (in $\mathrm{N} \cdot \mathrm{m}$ ).

Value of $M_{T}$ is obtained from

$$
M_{T}=\frac{1}{2} d_{y} T_{x} \approx \frac{1}{2} d_{z} T_{x}=\frac{1}{2} d_{z} T \sin \theta=\frac{1}{2} d_{z} P f \sin \theta,
$$




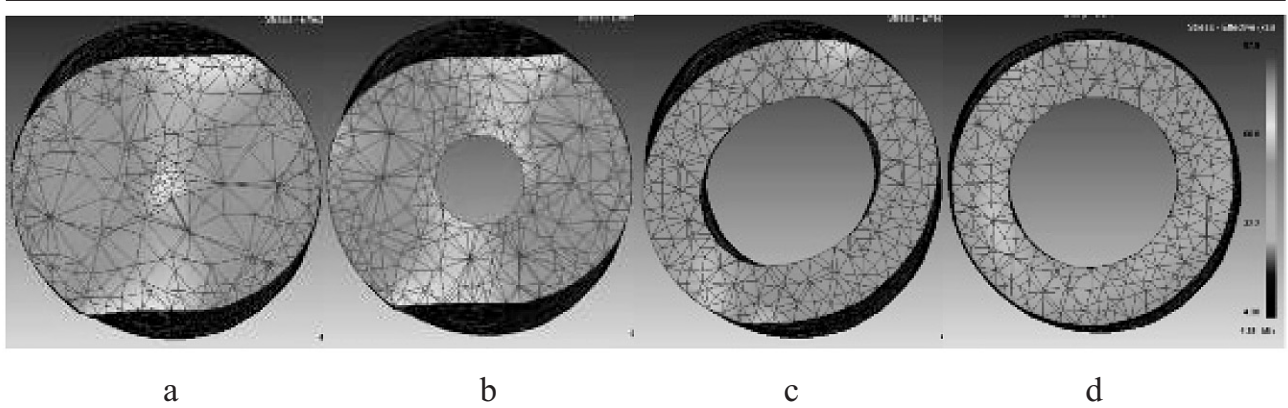

Fig. 5. Cross-sectional area in different deformation areas: (a) preparing; (b) piercing; (c) rolling; (d) turning round.

where $\theta$ is the angle of friction, $P$ is the positive pressure, $\mathrm{kN}, d_{z}$ is the billet diameter, $\mathrm{mm}, f$ is the friction factor, and $T$ is the friction force, $\mathrm{kN}$. We have

$$
\begin{gathered}
M_{P}=P_{y z} a \approx P a, \\
a=\frac{b}{2}\left(\frac{D+d_{z}}{D}\right),
\end{gathered}
$$

where $D$ is the maximum diameter of the roller, mm, $b$ is the contact width, mm, and $a$ is the arm of the force, $\mathrm{mm}$.

The first bite condition can be rewritten as

$$
n\left(T_{y}-P_{y}\right)+P^{\prime} \geq 0
$$

where $n$ is the number of rollers, $P^{\prime}$ is the thrust force, $\mathrm{kN}, T_{y}$ is the axial component of friction, $\mathrm{kN}$, and $P_{y}$ is the axial component of the positive pressure, kN. Both axial components are given by

$$
\begin{gathered}
T_{y}=T \cos \theta=P f \cos \theta, \\
P_{y}=P \sin \alpha_{1} .
\end{gathered}
$$

The equation of the second bite condition is

$$
n\left(T_{y}-P_{y}\right)+P^{\prime}>Q
$$

where $Q$ is the axial resistance of plug, $\mathrm{kN}$. The value of $Q$ can influence the bite condition directly.

Area $I I$ is the piercing area. The solid billet deforms into a tube with hollow center. The contact changes from metal and plug to plug and cone belt. The deformation at the exit of area $I I$ is shown in Fig. 5b. The wall thickness is gradually reduced in this area as the distance between the roller surface and plug decreases. Because the guide plate prevents transverse flow of the compressed metal, the main deformation in this area is axial.

Area $I I I$ is the rolling area. Here the plug generatrix and the roller generatrix run parallel to each other, so the rolling reduction is very small. The internal and outer surface quality and dimensional accuracy are improved. The deformation of the work piece at the exit of area III is shown in Fig. 5c. 
Area $I V$ is the turning round area. The deformation of the work piece at the exit of area $I V$ is shown in Fig. 5 d.

2.2. Variation of the Piercing Force with Time. The force data were extracted from simulation results. From Fig. 6 we can see that from 0 to $1 \mathrm{~s}$ the billet is initially bitten by the tapered inlet and then the plug. After $2 \mathrm{~s}$ the billet enters a stable rolling stage where the average positive pressure force is $3.48 \mathrm{kN}$.

The simulation results of axial and cross forces are shown in Fig. 7. In the stable rolling stage, the average axial force $Q$ is $788 \mathrm{~N}$ and the cross force $P_{L}$ is $477 \mathrm{~N}$.

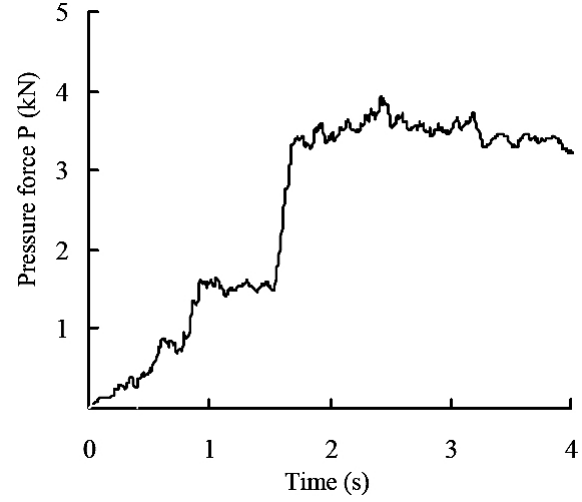

Fig. 6. Variation of positive pressure force.

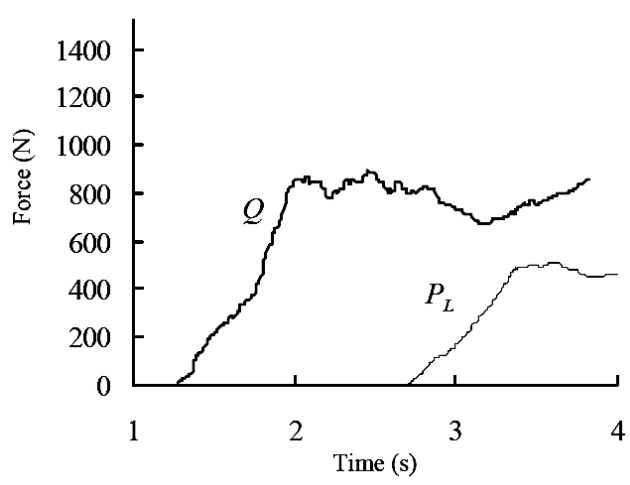

Fig. 7. Axial and cross forces.

2.3. Impact of Plug Position on the Piercing Force. During stable rolling, we extracted 40 positive pressure forces and calculated the average value. Figure 8 shows the pressure dependence on given different plug positions. When the plug position is zero, the rolling force is $3.6 \mathrm{kN}$. However, with the plug position of $25 \mathrm{~mm}$, the rolling force decreases to $3.4 \mathrm{kN}$.

As the plug position advances, the rolled workpiece encounters resistance sooner, the perforating speed slows down, and the rolling pitch decreases. Meanwhile, the contact area between the top of the roller inlet and the roll is reduced, which leads to a reduction of the rolling force. When the plug position exceeds $25 \mathrm{~mm}$, the rolling force increases rapidly because the contact length of the plug roller tube is too short and rolling cannot achieve an effective rotation.

Figure 9 presents the simulation results about the variation of axial force with plug position. As we can see, when the plug position is less than $25 \mathrm{~mm}$, the axial force keeps decreasing with advancing the plug position. This may be attributed to a decline of the piercing speed, a rise of the axial slippage, and a decrease of compression in unit area, which causes a reduction of the force acting on the top of the head. With the plug position of more than $25 \mathrm{~mm}$, the axial force increases rapidly because the contact length between the plug roller and rolled workpiece is too short, and therefore cannot generate effective rotation and rotating cross-forging effect.

According to the above analysis of the rolling and axial forces, suitable plug positions range from 10 to $25 \mathrm{~mm}$ where the forces are minimal.

2.4. Effect of Plug Position on the Equivalent Strain Rate. From the simulation results of the two-roll rotary piercing process, the variations of strain rates with the plug position over a longitudinal cross section were extracted and plotted in Fig. 10. Near the bite point, the equivalent strain rate is close to a maximum value of about $85 \mathrm{~s}^{-1}$. The strain rate inside the rolled piece is less than that at the surface. As the plug advances, the strain in the metal expands correspondingly until the plastic zone of the rolled piece is connected. 


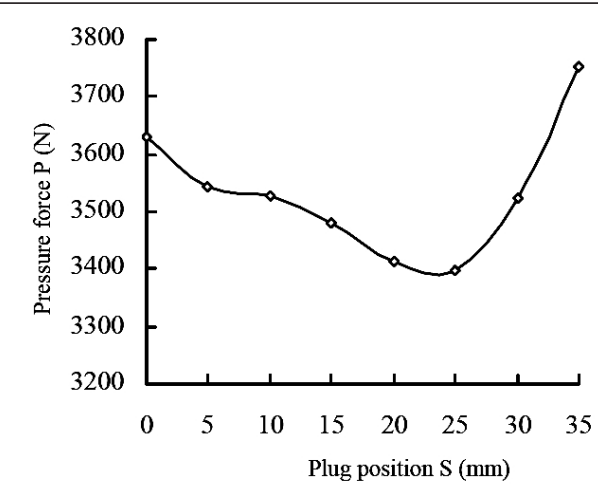

Fig. 8

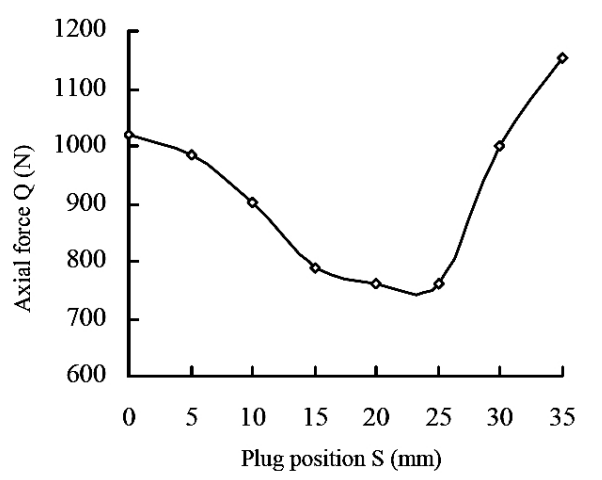

Fig. 9

Fig. 8. Variation of rolling pressure with plug position.

Fig. 9. Variation of axial force with plug position.

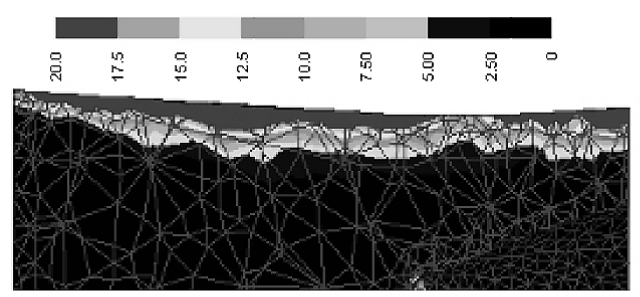

$\mathrm{S}=5 \mathrm{~mm}$

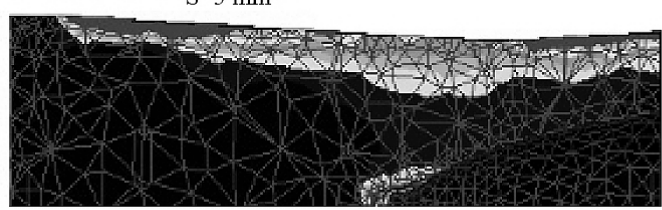

$\mathrm{S}=15 \mathrm{~mm}$

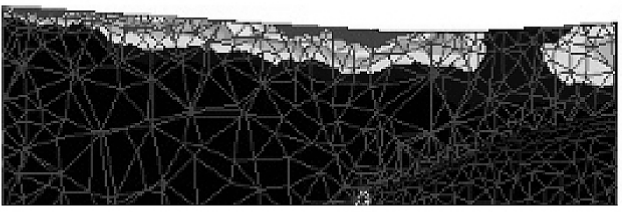

$\mathrm{S}=10 \mathrm{~mm}$

Fig. 10. Strain rate distribution along the longitudinal cross section.

Similarly, the strain rate contours in transverse cross sections were extracted, as shown in Fig. 11. The maximum value of the strain rate appears near the bite point. In the longitudinal direction, the strain rate decreases from inlet to exit, in line with the general law of rolling. The area of the maximum equivalent strain rate in the rolling surface begins further out as the value of $y$ increases, resulting from the feed angle between the incline surface of the rolled workpiece and the roll contact surface with respect to the $y$-axis. As the plug position advances, the area of the maximum strain rate increases, and the deformation zone expands accordingly. When the plug position is more than $15 \mathrm{~mm}$, the rolling plastic deformation zone is connected, and meanwhile the deformation resistance decreases.

2.5. Influence of Plug Position on the Dimension Precision of Rolled workpieces. The exit dimensions of the rolled workpiece need to be examined with different plug positions. The influence of plug position on the dimension precision can be described by

$$
\begin{gathered}
S_{D}=\sqrt{\frac{1}{k-1} \sum_{i=1}^{n}\left(x_{i}-\bar{x}\right)^{2}}, \\
\Delta=\frac{d_{\text {max }}-d_{\text {min }}}{\bar{d}} .
\end{gathered}
$$




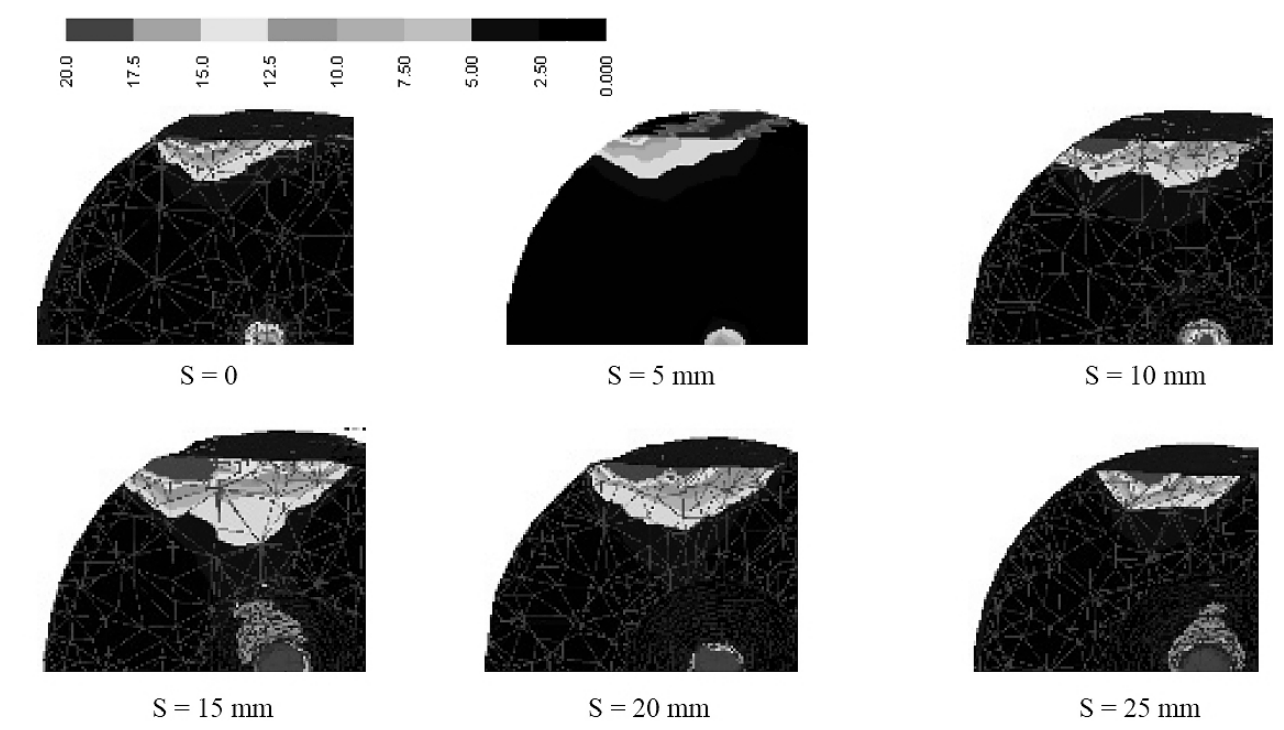

Fig. 11. Strain rate distribution in the transverse cross section.

A cross section within the stable rolling zone is selected for this study. Three sets of data, including the outer diameter, inner diameter, and wall thickness, are recorded with ten readings in each group. It is found that the plug position has an evident effect on the outlet size of rolling. When the plug advances more than $15 \mathrm{~mm}$, the difference between ovality and wall thickness of the outlet section is significantly reduced. Moreover, the precision of capillary dimensions is improved.

Extracting 100 data points in each group for various transverse cross sections of the capillary, we calculated standard deviations of the outer and inner diameters of the capillary with different plug positions. The variation of dimensional precision of the capillary (Fig. 12) shows that, with the plug positions between 0 and $20 \mathrm{~mm}$, the standard deviation of the outer and inner diameters is significantly reduced.

2.6. Influence of Feed Angle on the Dimension Precision of Rolled Pieces. Four models were generated by computer with different feed angles of $8,12,14$, and $16^{\circ}$. The influence of feed angle on the dimension precision of rolled pieces was obtained after simulations using different feed angle models.

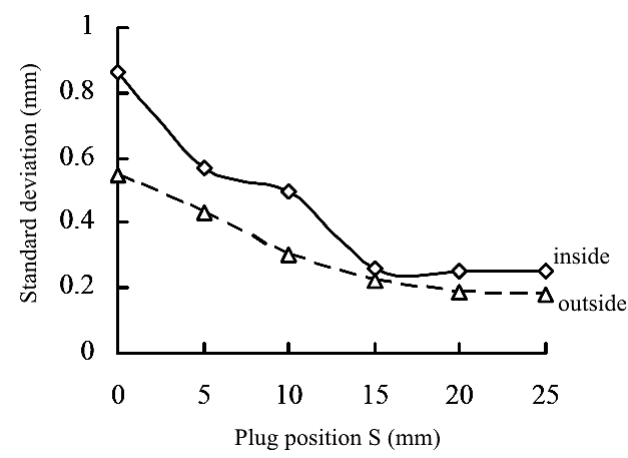

Fig. 12

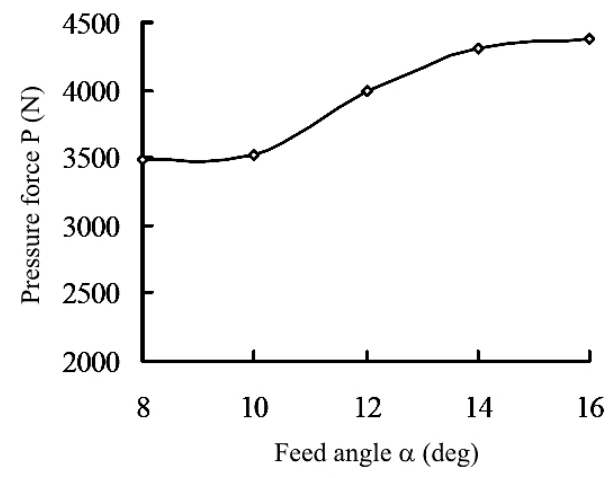

Fig. 13

Fig. 12. Variation of standard deviation with plug position.

Fig. 13. Variation of rolling pressure with feed angle. 
As shown in Fig. 13, the rolling force increases with increasing the feed angle. A slight increase of the rolling force occurred when the feed angle increased from 8 to $10^{\circ}$ and 14 to $16^{\circ}$. The rolling force increases exponentially when the feed angle increases from 10 to $14^{\circ}$.

The equivalent strain distribution in the cross section with different feed angles (Fig. 14) is roughly uniform. As the feed angle increases, the axial velocity increases as well. The metal after the deformation zone is subjected to reduced pressures. With fewer cycles of alternating stress, heterogeneity in the deformation of the metal tends to subside.

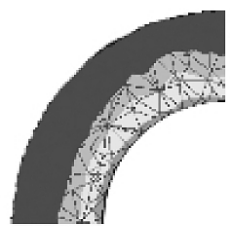

$\alpha=8^{\circ}$

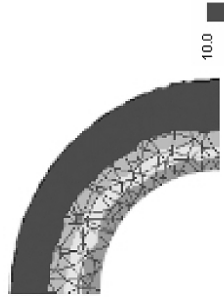

$\alpha=10^{\circ}$

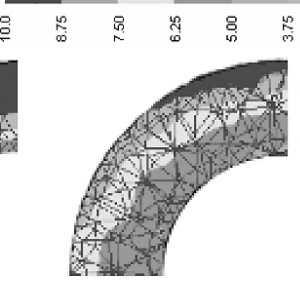

$\alpha=12^{\circ}$

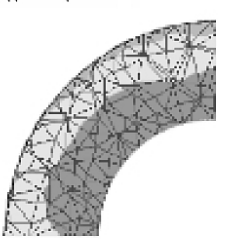

$\alpha=14^{\circ}$

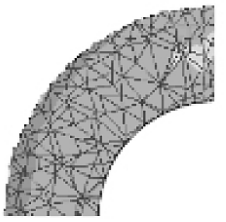

$\alpha=16^{\circ}$

Fig. 14. Equivalent strain distribution in transverse cross section.

The standard deviations of the capillary outer and inner diameters with different feed angles are shown in Fig. 15. From simulation results, 100 values of the diameter were extracted in transverse cross sections to calculate the standard deviation. The standard deviation of the small characterization data set of discrete degree is reduced, yielding a high precision of the capillary size. When the feed angle varies from 8 to $10^{\circ}$, the standard deviation seems small and the size precision of the capillary varies little. With the feed angle between 10 and $16^{\circ}$, the standard deviations of the outer and inner diameters increase significantly, which leads to a reduced size precision. Thus, increasing the feed angle to improve the rolling speed is not feasible.

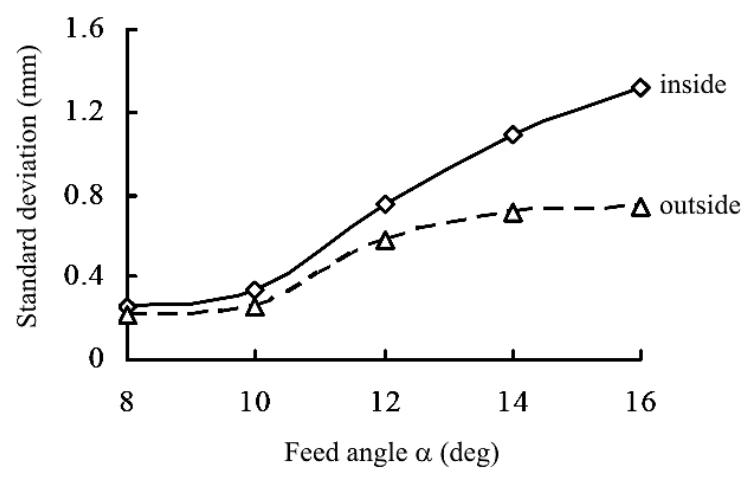

Fig. 15. Variation of standard deviation with feed angle.

2.7. The Mannesmann Effect. During cross rolling with certain process parameter settings, the solid workpiece would experience longitudinal tears, and hence deform the cavity. Based on this phenomenon, the Mannesmann brothers invented the two-roller cross-rolling mill in the 1920 s.

The deformation of the cavity is associated with the stress and strain state in the metal. Many studies have been focused on cavity formation. However, because of the complexity of the cross-rolling process, no mechanism has been established so far. In this work, we 
used the 3-D rigid plastic FEM of the two-roller cross perforation process to analyze the cavity mechanism in detail.

To analyze the stress state at the center of the workpiece, stress values of the critical section were extracted from the simulation results. Three curves corresponding to the variation of vertical shear stress (Fig. 16a) show that, at the origin $\tau_{x y}$ is positive whereas $\tau_{y z}$ and $\tau_{z x}$ are negative. The three curves for the variation of horizontal shear stress (Fig. 16b) show that, at the origin $\tau_{x y}$ is negative whereas $\tau_{y z}$ and $\tau_{z x}$ are positive. Because the workpiece rotates clockwise, after a $1 / 4$ cycle, the $x$-axis points would have shifted to the $z$-axis position. The shear stress state of the workpiece center changes the signature from $(+,-,-)$ to $(-,+,+)$. Thus, the metal of the workpiece center is subjected to alternating shear stresses.

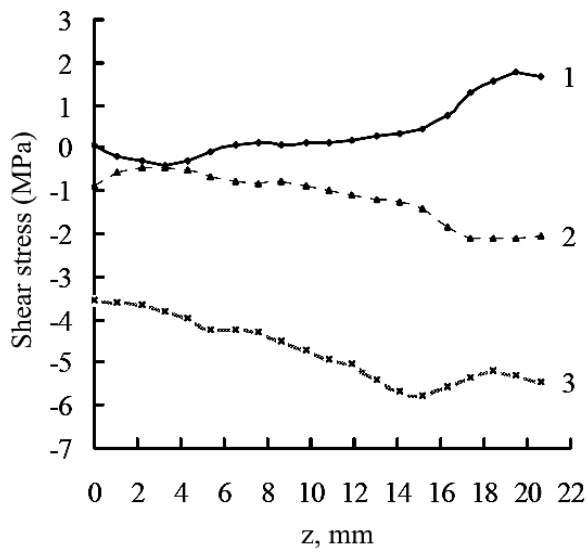

a

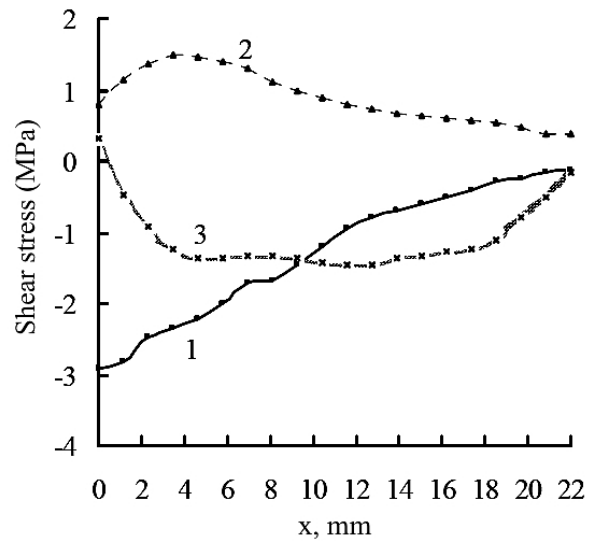

b

Fig. 16. Stress distributions for vertical and horizontal cross sections: (a) variation of shear stress with $z$ coordinate; (b) variation of shear stress with $x$ coordinate $\left[(1) \tau_{x y} ;(2) \tau_{y z}\right.$; (3) $\left.\tau_{z x}\right]$.

The curves for the longitudinal variation of normal stress (Fig. 17) show that the normal stress $\sigma_{x}$ near zero leads to a large tensile stress that decreases as $y$ increases. Similarly, $\sigma_{y}$ near zero is also a tensile stress with alike behavior but with values smaller than $\sigma_{x}$. The normal stress $\sigma_{z}$ near zero is a compressive stress over the whole perforation preparation area. Above all, the normal stress of the workpiece center has the signature $(+,+,-)$.

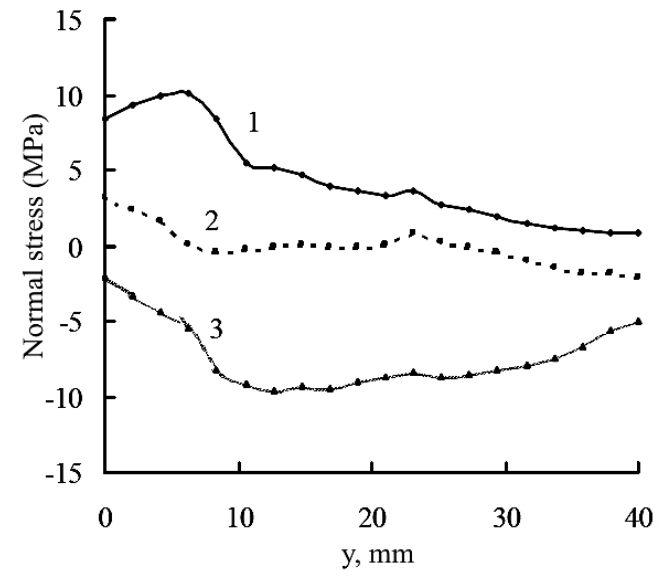

Fig. 17. Main stress distribution in a longitudinal cross section $\left[(1) \sigma_{x} ;\right.$ (2) $\sigma_{y}$; (3) $\left.\sigma_{z}\right]$. 
In summary, the metal at the center is deformed by an alternating shear stress and large tensile normal stress in the cross-piercing process. The peak stress of 55SiMnMo steel at $1050^{\circ} \mathrm{C}$ is $76.44 \mathrm{MPa}$, which is measured by hot isothermal compression tests. The stress state of the pre-plug metal is the tear rolled state so that no cavity is formed in the head before folding begins.

3. Experiments. Experiments were performed in a drilling tools factory, Hubei, China. The factory produces b22-type drill steel with $55 \mathrm{SiMnMo}$ steel using the heatpiercing heat-rolling method. The system makes $45 \mathrm{~mm}$ diameter solid bar stock to b22-type hexagon drill steel with hollow center. After being cut to length, a solid round billet experiences mechanical centering, and then is heated to $1050^{\circ} \mathrm{C}$ with five DGF-T-502 frequency induction heaters. The difference between inside and outside temperatures is controlled less than $50^{\circ} \mathrm{C}$. Next, the solid billet would be cross-rolled and perforated by a $50 \mathrm{~mm}$ diameter Mannesmann two-roll cross rolling mill (Fig. 18). The capillary billet can be reduced using an Accel three-roll cross rolling mill. The final rolling forming of the workpiece is performed by a special hexagonal rolling mill.

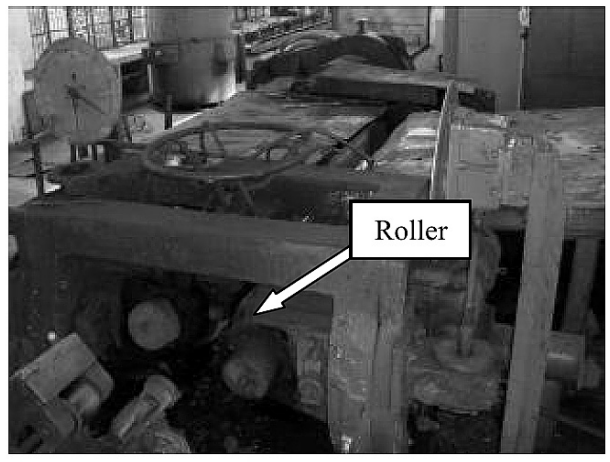

Fig. 18. Photo of the Mannesmann two-roll cross rolling mill.

According to the original production parameters of the factory, the piercing plug position was $S=10 \mathrm{~mm}$ and the feed angle was $\alpha=8^{\circ}$. Then, keeping all other parameters constant, we changed to $S=20 \mathrm{~mm}$ and $\alpha=10^{\circ}$, and obtained a cross section of finished product. These measurements and comparisons clearly demonstrate that the changes of parameters can improve the dimensional precision of drill steels.

Conclusions. In this paper, the rigid plastic finite element method is used to analyze the Mannesmann piercing process in drill steel production. Three-dimensional thermalforce coupling FEM models with different plug positions and feed angles were generated. The conclusions are as follows:

1. The plug position affects the rolling force and dimensional accuracy. According to the analysis of rolling force, the workpiece can be bitten successfully when $S$ is between 10 and $25 \mathrm{~mm}$. By advancing the plug position, the strain of the metal expands correspondingly until the plastic zone of the rolled piece is connected. Changing $S$ from 10 to $20 \mathrm{~mm}$ can improve the ovality of the drilled hole.

2. The feed angle affects the rolling force and dimensional accuracy. Changing $\alpha$ from 8 to $10^{\circ}$ can improve the ovality of the drilled hole.

3. The metal in the center is deformed by alternating shear stresses and strong tensile normal stresses during the cross piercing process.

Acknowledgments. The authors wish to thank Enlin Yu, Tao Yan, and Guoju Zhang. This work was supported in part by a grant from Qinhuangdao Science and Technology support program (No. 201101A044) and National Natural Science Foundation of China (No. 31170956). 
1. A. S. Belousov and P. P. Konshin, "Improving the quality of hollow drill steel," Metallurgist, 1, 103-111 (1957).

2. F. R. Larkin, N. A. Kudrya, A. M. Chubilin, and N. S. Artemenko, "Technique of manufacturing drill rods," Metal Sci. Heat Treat., 16, 134-135 (1974).

3. Yu. A. Postonogov and V. V. Nikiforov, "New shape of leader pass for rolling hexagons," Metallurgist, 24, 285-287 (1980).

4. N. G. Petrov and R. E. Pasynkov, "Deformation and stability of drill rod," J. Mining Sci., 29, 132-135 (1993).

5. Song Shouzhi, L. Rong, Tang Chun'an, and Xu Xiaohe, "Dynamic response of fatigue strength of drill rod to theoretical load spectrum of rock drill," J. Northeastern Univ., 17, 579-583 (1996).

6. Xiong Jiaze, "The study of the parameter on the hollow steel fatigue life test," Modern Machinery, 1, 89-91 (2011).

7. Enlin Yu, Yuqian Zhao, and Tao Yan, "Modeling of hot deformation behavior of 55SiMnMo medium-carbon steel," J. Iron Steel Res., 20, No. 11, 125-130 (2013).

Received 20. 10. 2014 